\title{
Role of body temperature in the onset of, and recovery from, hypothermia-induced anterograde amnesia
}

\author{
RICK RICHARDSON, VICTOR GUANOWSKY, STEPHEN T. AHLERS, \\ and DAVID C. RICCIO \\ Kent State University, Kent, Ohio
}

\begin{abstract}
The onset of, and recovery from, hypothermia-induced anterograde amnesia in rats was examined in two experiments. The first experiment demonstrated that recooling subjects shortly prior to testing alleviated anterograde amnesia. However, this recovery of memory was found to be temperature dependent: Subjects recooled and tested at $29^{\circ} \mathrm{C}$, the temperature at training, demonstrated recovery, whereas subjects allowed to rewarm to $33^{\circ}$ did not. The role of core body temperature in the onset of anterograde amnesia was examined in Experiment 2. Animals were tested $30,120,360$, or $1,440 \mathrm{~min}$ after one-trial punishment training. Subjects tested after 30 min were significantly cooler than the other subjects and exhibited good retention, whereas subjects tested after 360 or $1,440 \mathrm{~min}$ did not. Thus, although the onset of hypothermia-induced retrograde amnesia has been found to be temperature independent, onset of anterograde amnesia appears to be more closely linked to the subject's temperature. The similarity between anterograde amnesia and the more traditional state-dependent retention paradigm is discussed.
\end{abstract}

Experimental investigations of anterograde amnesia (AA) have been relatively sparse in comparison with the wealth of research on retrograde amnesia (RA). A likely reason for the disparity in emphasis is the difficulty involved in determining whether or not target information was originally acquired in the anterograde condition, since most amnestic agents have severe, it transient, effects on sensorimotor capabilities. Before performance deficits at a later test can be properly referred to as amnesia, care must be taken to ensure that the subject is capable of acquiring the target information as well as performing the appropriate response. If subjects are incapable of learning the target information (or performing the appropriate task), it seems preferable analytically to refer to subsequent impairment as a "learning deficit" or an "encoding failure" rather than an "amnesia." Although this distinction has long been accepted in research on experimentally induced amnesia in animals, it has not always been made in research on human amnesia patients (cf. Butters \& Albert, 1982). However, the importance of ensuring that human amnesia subjects have acquired information initially has become a more central issue in recent years (Huppert \& Piercy, 1978).

In studies on experimentally induced amnesia in animals, several approaches have been taken to deal with this difficulty (Gardner, Glick, \& Jarvik, 1972; Kopp, Bohdanecky, \& Jarvik, 1968; Springer, Schoel,

This research was supported by NIMH Grant MN37535 to D.C.R. Requests for reprints should be sent to: Rick Richardson, Department of Psychology, Kent State University, Kent, OH 44242.
Klinger, \& Agranoff, 1975), but the solutions have been either indirect or subject to alternative interpretations. Recently, however, Richardson, Riccio, and Morilak (1983) reported what appears to be an unequivocal example of AA. Rats receiving punishment training while at lowered body temperature $\left(29^{\circ} \mathrm{C}\right)$ showed excellent retention when tested shortly after the acquisition trial but poor retention (AA) when tested $24 \mathrm{H}$ after training. Because hypothermia might simply alter locomotor activity in a way that would mimic associative learning at the critical shortinterval test, performance controls receiving equivalent cooling were tested shortly after receiving noncontingent footshock (NCFS) in lieu of training. These subjects showed no evidence of "learning." Moreover, the AA effect was obtained using a withinsubjects as well as a between-groups design: When rats that showed strong retention at the immediate test were retested $24 \mathrm{~h}$ later, performance remained high for subjects trained in the normothermic state but declined sharply for those trained while cool. In addition, the anterograde memory loss effect is not attributable simply to nonspecific interference from prior hypothermic treatment, because subjects that were cooled but permitted to rewarm to near normothermic levels prior to training showed no memory impairment.

While these findings provide a reasonably clear demonstration of rapid forgetting induced by an anterograde treatment, a number of important issues remain unanswered. One general principle of interest concerns the parallelism (or lack thereof) between anterograde and retrograde induced sources of 
memory loss. While the asymmetry in procedures may preclude precise quantitative comparisons, it should still be possible to determine whether conditions known to influence RA exert qualitatively similar effects on anterograde loss. The two experiments reported here represent an initial attempt to explore this question. Using hypothermia-induced AA, Experiment 1 , investigated reversability of the memory loss; Experiment 2 examined the onset of $\mathbf{A A}$ with respect to recovery of body temperature. Both the reversability and onset of amnesia have been extensively investigated in the RA paradigm (Hinderliter, Webster, \& Riccio, 1975; Mactutus and Riccio, 1978; Miller \& Springer, 1972; Thompson \& Grossman, 1972; Thompson \& Neely, 1970).

\section{EXPERIMENT 1}

In their initial study, Richardson et al. (1983) attempted to reverse hypothermia-induced anterograde amnesia by exposing subjects to noncontingent footshock (NCFS) 20 min prior to testing. While NCFS has been shown to reverse retrograde amnesia produced by hypothermia or hyperthermia (Mactutus, Ferek, \& Riccio, 1980) or electroconvulsive shock (Miller \& Springer, 1972), it failed to produce a statistically reliable alleviation of anterograde amnesia. This negative outcome must be viewed cautiously, however, since only a single reactivation condition was employed. Instead of altering parameter values in the NCFS situation, we chose another procedure in attempting to recover the memory.

Because recooling prior to testing has proven very effective in reversing hypothermia-induced retrograde amnesia (Hinderliter et al., 1975; Mactutus \& Riccio, 1978; Riccio, Mactutus, Hinderliter, \& McCutcheon, 1979), it would seem that this treatment would be a particularly appropriate agent with which to alleviate anterograde memory loss. Furthermore, the fact that the severity of body cooling can be readily manipulated, as well as specified, would permit us to determine if there was a relationship between level of recooling and extent of memory recovery. On the other hand, persistent further failures to obtain recovery from anterograde amnesia would suggest an important difference between it and the memory loss produced in retrograde treatments. At a theoretical level, evidence of irreversible memory loss in anterograde amnesia would imply that a rapid loss of storage, rather than retrieval failure, mediated the effect of prograde treatments. Accordingly, this experiment was designed to determine whether a second hypothermia treatment shortly prior to testing could result in recovery of memory.

\section{Method}

Subjects. The subjects were 72 male adult rats, 91-144 days of age, purchased from the Holtzman Company. The animals were individually housed in standard wire-mesh cages and ear-punched for identification. Food and water were available ad lib.

Apparatus. The training and testing apparatus was a $38 \times 18 \times$ $21 \mathrm{~cm}$ Plexiglas chamber divided into two equal compartments. One compartment, including the lid, was painted black. The other compartment was painted white and had a clear Plexiglas lid. A 15 -W light bulb was suspended $30 \mathrm{~cm}$ over the center of the white compartment. A guillotine doorway $(8 \times 8 \mathrm{~cm})$ connected the two compartments. The floor of the apparatus consisted of $2-\mathrm{mm}$ stainless steel grids spaced $1 \mathrm{~cm}$ apart. A matched impedence shock source (Campbell \& Teghtsoonian, 1958) was connected to the grids on the black side, to which a scrambled footshock $(250 \mathrm{~V} / 3 \mathrm{sec})$ could be delivered. Behavior for each subject was monitored visually by means of a tilted mirror placed under the center of the apparatus.

Procedure. The subjects were handled 2-3 min daily for 2 days prior to training. They were then randomly divided into six groups. The general procedure most of these groups experienced involved four stages. First, an animal was exposed to deep body cooling (hypothermia) prior to training. Hypothermia was induced by dunking the rat up to the neck in $3^{\circ}-4^{\circ} \mathrm{C}$ water until its colonic temperature, as measured by a Yellow Springs telethermometer, dropped to $21^{\circ} \pm 1^{\circ} \mathrm{C}$. Second, when it had rewarmed to $29^{\circ} \mathrm{C}$, the animal was fear conditioned. Conditioning consisted of placing the rat in the white side of the training apparatus facing away from the door. After $10 \mathrm{sec}$, the door was lifted. The animal had $60 \mathrm{sec}$ to cross over into the black side, with all four paws, at which time the door was shut and a 3-sec scrambled footshock was delivered. Third, some of the animals received a second hypothermia treatment, similar to the one described, $24 \mathrm{~h}$ after training. Fourth, all animals were given a $10-\mathrm{min}$ passive avoidance test. This consisted of placing the rat on the white side of the apparatus, facing away from the door. After $10 \mathrm{sec}$, the door was removed. Initial latency to cross into the black side and total time spent in the white (safe) compartment (TTW) were the measures recorded.

Four groups of animals were cooled prior to conditioning; of these, three received recooling $24 \mathrm{~h}$ later and were tested when their colonic temperature was $29^{\circ} \mathrm{C}$ (same as training), $31^{\circ} \mathrm{C}$, or $33^{\circ} \mathrm{C}$. To insure that anterograde amnesia was obtained, a fourth group, trained while cool, was tested under normothermic $\left(36^{\circ} \mathrm{C}\right)$ conditions $24 \mathrm{~h}$ later (hypo-train). A fifth group received cooling, but received a NCFS treatment instead of conditioning. These animals were placed in the training apparatus, but, upon crossing into the black side, they were removed, taken to another room, placed in an unpainted $21 \times 17.5 \times 19.5 \mathrm{~cm}$ wood box, and given a footshock comparable to that of trained subjects. Twenty-four hours later, they received recooling and were "tested" at $29^{\circ} \mathrm{C}$. A final group was conditioned and tested $24 \mathrm{~h}$ later (both events in the normothermic state) to provide an index of strength of the fear memory under standard retention conditions. The group that was tested at $31^{\circ} \mathrm{C}$ had 9 subjects; all other groups had 10 subjects each.

\section{Results and Discussion}

Thirteen animals were removed from the experiment for failure to cross over in $60 \mathrm{sec}$ at training, failure to survive hypothermia, or experimenter error. For the remaining animals, no significant differences were found among the initial cross-through latencies with a Kruskal-Wallis ANOVA $(\mathrm{H}=8.8$, $\mathrm{p}>.05$ ). Additional analysis with Kruskal-Wallis ANOVA indicated significant group differences on the latencies at testing $(\mathrm{H}=23.9, \mathrm{p}<.001)$ and the TTW measures $(H=23.7, p<.001)$. Because subsequent pairwise comparisons with the Mann-Whitney $\mathrm{U}$ test yielded a similar pattern of results with both the latency and the TTW measures, only the results 
with the latency measures are presented. The median latencies are shown in Figure 1. The significant difference between trained-only subjects and the group that was conditioned while cool but not recooled at testing $(U=6, p<.002)$ represents a replication of earlier findings of anterograde amnesia (Richardson et al., 1983). Of particular interest here are the recovery data. The figure suggests, and statistical analyses confirm, that temperature-dependent recovery from AA was obtained. Mann-Whitney $U$ test performed on the latency data showed significantly longer latencies in the recooled animals tested at $29^{\circ} \mathrm{C}$ than in those tested in either the normothermic state (hypo-train) or at a slightly hypothermic level $\left(33^{\circ} \mathrm{C}\right)$ (Us $<19$, ps $\left.<.02\right)$. Furthermore, the recovery of memory appears to be a graded process inasmuch as animals tested at $31^{\circ} \mathrm{C}$ did not differ significantly from those tested at $29^{\circ} \mathrm{C}(\mathrm{U}=28, \mathrm{p}>$ $.05)$ or those tested at $33^{\circ} \mathrm{C}(\mathrm{U}=40, \mathrm{p}>.05)$. That test temperature rather than recooling treatment per se is important can be seen from the finding that the recooled animals tested at $33^{\circ} \mathrm{C}$ did not differ significantly from the group trained while hypothermic but tested without being recooled $(U=27.5, p>.05)$. Performance in the NCFS group, which was recooled and tested at $29^{\circ} \mathrm{C}$, was markedly inferior to the anterograde animals recooled and tested at $29^{\circ} \mathrm{C}$ $(U=18.5, p<.02)$. Thus, recovery in anterograde animals tested at $29^{\circ} \mathrm{C}$ cannot be a result of performance artifacts produced by footshock and cooling treatments. An indication of within-group variability is given by the semi-interquartile range (SIQR). The SIQRs were as follows: 225,160 , or $46 \mathrm{sec}$ for the HYPO/PA/recooled groups tested at $29^{\circ} \mathrm{C}, 31^{\circ} \mathrm{C}$, or $33^{\circ} \mathrm{C}$, respectively; $30 \mathrm{sec}$ for the

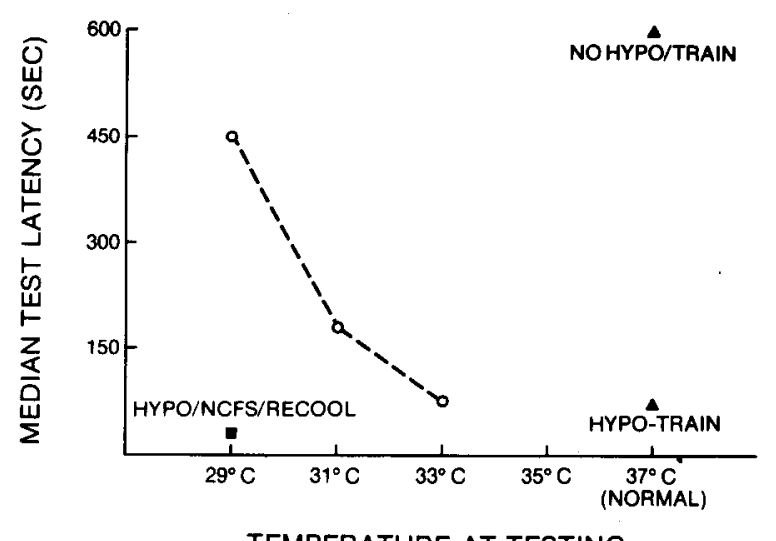

TEMPERATURE AT TESTING

Figure 1. Retention performance of subjects in Experiment 1. Three groups, trained while hypothermic, were recooled prior to test and allowed to rewarm to $29^{\circ} \mathrm{C}, 31^{\circ} \mathrm{C}$, or $33^{\circ} \mathrm{C}$. The HYPO/ NCFS/recool group received noncontingent footshock in lieu of training and was tested after recooling $\left(29^{\circ} \mathrm{C}\right)$. Of the two groups of rats not recooled prior to testing, one had been trained in the normothermic state (no HYPO/train) and served as a retention control; the other, trained while cool (HYPO/train), provided an index of the severity of anterograde amnesia.
$\mathrm{HYPO} / \mathrm{NCFS} /$ recooled group tested at $29^{\circ} \mathrm{C}$; and $221 \mathrm{sec}$ for the retention controls.

These data demonstrate that memory can be recovered following an anterograde amnesia procedure by reinstating the internal context present during original learning. Since recooling has also been shown to be effective in recovery of memory in retrograde amnesia (Hinderliter et al., 1975; Riccio et al., 1979), it appears that recoverability of memory in these paradigms share similar characteristics.

The graded recovery of performance, dependent upon subject's temperature at testing, is strikingly similar to the stimulus generalization gradients obtained in traditional "learning" studies. Strength of responding, seen here as alleviation of amnesia, varies as a function of similarity of test cues to training stimuli. The unusual feature of the present study is that body temperature, an apparently irrelevant contextual state (cf. Spear, 1978), provides the source of stimulus control.

\section{EXPERIMENT 2}

With respect to retrograde amnesia (RA), previous findings from our lab have shown that a specific level of cooling is necessary to obtain RA (Mactutus, Riccio, \& Ferek, 1979; Riccio, Hodges, \& Randall, 1968 ) but that the actual onset of the amnesia appears to be independent of temperature (Mactutus \& Riccio, 1978). For example, subjects cooled to $21^{\circ} \mathrm{C}$ after passive avoidance (PA) training do not demonstrate a retention deficit until 12 to $16 \mathrm{~h}$ after the hypothermic treatment, which is long after their core body temperature returned to normal levels. This finding is similar to that of the delayed onset of retrograde amnesia induced by electroconvulsive shock (Geller \& Jarvik, 1968). With respect to hypothermiainduced anterograde amnesia (AA), however, no such data exist to show exactly when the retention loss becomes apparent and whether or not it is temperature dependent.

A second question concerns the level of cooling necessary to obtain the AA effect. In our previous study (Richardson et al., 1983), as well as in Experiment 1 here, rats were cooled to $21^{\circ} \mathrm{C}$ because this level of cooling is highly effective in producing RA (Riccio et al., 1968; cf. Wetsel, Riccio, \& Hinderliter, 1976). However, in the anterograde paradigm, subjects are allowed to rewarm to $29^{\circ} \mathrm{C}$ to permit the spontaneous locomotor activity required for training and testing. Although it is clear that the core body temperature must be below $33^{\circ} \mathrm{C}$ at the time of training in order to obtain AA (Richardson et al., 1983), it is not known if the initial deep cooling to $21^{\circ} \mathrm{C}$ is essential. If the "overcooling" procedure is necessary, then specifying body temperature at training does not adequately describe conditions producing AA - theoretically a potentially important considera- 
tion. Procedurally, of course, it would be simpler if the rewarming phase could be eliminated and subjects were merely cooled to the criterion $\left(29^{\circ} \mathrm{C}\right)$ level.

The present experiment was designed to trace the onset of the retention deficit over several hours to see if the retention loss was temperature dependent. An ancillary aim was to determine whether the anterograde amnesia effect was influenced by the level of cooling prior to training.

\section{Method}

Subjects. One hundred and nineteen adult male rats purchased from the Holtzman Company served a subjects. They were housed identically to those in Experiment 1.

Apparatus. The apparatus was the same as that in Experiment 1.

Procedure. All handling, conditioning, and testing procedures were identical to those previously employed.

Four groups received deep body cooling to $21^{\circ} \mathrm{C}$ and were allowed to rewarm to $29^{\circ} \mathrm{C}$ under room temperature conditions (circa $25^{\circ} \mathrm{C}$ ) before receiving training. Another four groups received moderate hypothermia to $29^{\circ} \mathrm{C}$, were allowed several minutes to stabilize at that temperature, and then were trained. Both punishment training and passive avoidance testing were conducted in the same manner as in Experiment 1 . However, subjects were tested for retention $30,120,360$, or 1,440 min following training. To control for combined systemic effects of hypothermia and shock, an additional group of animals that received hypothermia (either deep or moderate), followed by NCFS exposure, was tested 30 min later. Another group of subjects, a retention control (RC), was simply given fear conditioning and then tested for retention $1,440 \mathrm{~min}$ after conditioning.

As in Experiment 1, the dependent measures used to assess retention were latency to enter the black compartment and total time spent on white (TTW) during a 10-min test. In addition, each subjects' core body temperture was taken immediately after the test session.

\section{Results and Discussion}

Twenty animals were discarded from the study either for failing to cross into the dark compartment at training within $60 \mathrm{sec}(13)$ or as a result of procedural error (7). Subjects were replaced as needed to maintain Ns between 10 and 14 in each group, except for the cooled/NCFS groups, which had Ns of 6 .

A preliminary analysis comparing the groups allowed to rewarm to $29^{\circ} \mathrm{C}$ and those cooled only to that level indicated no differences on initial training latencies, retention measures (test latency and TTW), or body temperature at the time of testing. Thus, these conditions were combined for further analyses.

A Kruskal-Wallis ANOVA on the combined scores indicated no differences among the various conditions on initial cross-through latencies at the time of training $(\mathrm{H}=5.98, \mathrm{p}>.10)$. At testing, however, a significant treatment effect was observed with latency $(\mathrm{H}=22.9, \mathrm{p}<.001)$, TTW $(\mathrm{H}=33.1, \mathrm{p}<$ $.001)$, and core body temperature $(\mathrm{H}=23.7, \mathrm{p}<$ .001 ) across the four retention intervals.

The median test latencies of the various groups are shown in Figure 2. The data point for the immediate test (1-min train-test delay) was obtained in our initial demonstration of hypothermia-induced

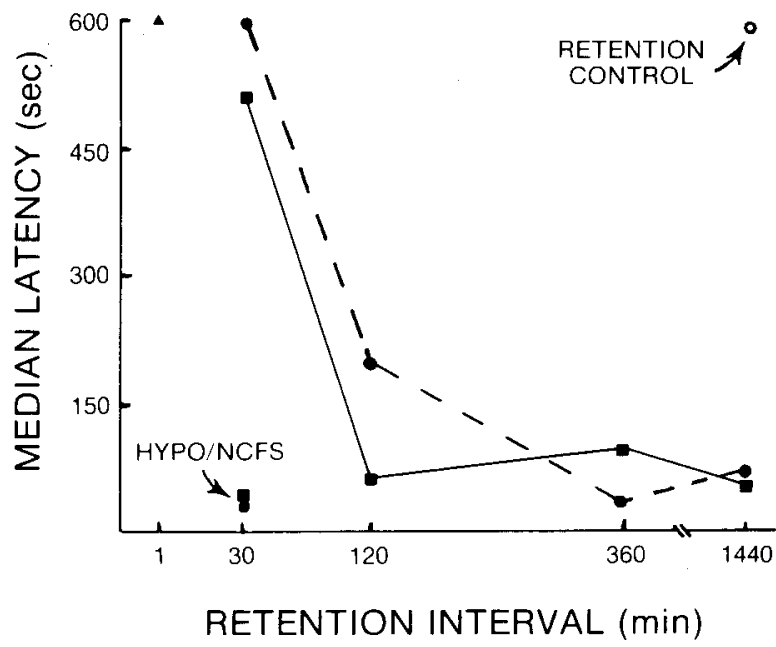

Figure 2. Test performance 30, 120, 360, and 1,440 min following training in Experiment 2. Filled rectangles represent performance of animals initially cooled to $29^{\circ} \mathrm{C}$, and filled circles represent performance of animals cooled to $21^{\circ} \mathrm{C}$ initially. Animals receiving a noncontingent footshock in lieu of training (NCFS) were tested only at the 30-min interval. The data point at the 1-min interval is taken from an earlier experiment.

AA (Richardson et al., 1983) and is presented for visual comparison purposes but is not included in the statistical analysis. Mann-Whitney U tests, corrected for ties, were used to make comparisons between groups. As can be seen in the figure, subjects trained and tested while in a cool state, showed near maximum retention (criterion level acquisition) immediately after conditioning. Evidence for a relatively rapid onset gradient of AA in this study is provided by the fact that rats tested for retention 30 min after training demonstrated slightly, but significantly, poorer retention (partial amnesia) than did the retention controls $(\mathrm{z}=2.08, \mathrm{p}<.02)$, but significantly better retention (i.e., longer latencies) than either the $360-\min (\mathrm{z}=1.89, \mathrm{p}=.058)$ or the $1,440-\mathrm{min}(\mathrm{z}=$ $2.09, p<.02)$ groups. No differences were found between the 360 - and 1,440 -min groups $(z=1.9, p>$ $.05)$, both of which differed from the retention control $(\mathrm{zs}>3.4$, ps $<.006)$. In addition, performance in both of these latter groups was comparable to that of untrained controls receiving hypothermia and NCFS, indicating that virtually complete retention loss occurred within $360 \mathrm{~min}$.

The short latencies of the untrained group (HYPO/ NCFS) are important in evaluating the performance of the trained group tested at $30 \mathrm{~min}$. The combined effects of the treatment per se produced latencies 30 min later that were substantially and significantly $(z=2.44, p<.01)$ lower than those of subjects trained while cool and tested after a 30 -min retention interval. Thus, after a short retention interval, the test scores of subjects trained while cool reflect good retention rather than elevated latencies due to stress artifacts. Analysis of the TTW measure yielded a 
imilar pattern of results, but with this measure it was also found that cooled subjects tested 120 min after raining differed significantly from those tested after sither $30 \min (\mathrm{z}=2.31, \mathrm{p}<.01)$ or $1,440 \min (\mathrm{z}=$ $3.06, \mathrm{p}<.001)$.

There was substantial variability among the various group scores. SIQRs for the latency measure were $284,202,178$, and $56 \mathrm{sec}$ for the HYPO/PA zroups tested after $30,120,360$, and $1,440 \mathrm{~min}$, respectively, $11 \mathrm{sec}$ for the HYPO/NCFS group, and ) sec for the retention controls. The SIQRs for the ITW measure for the corresponding groups were 76 , $214,233,154,35$, and $0 \mathrm{sec}$.

These data replicate our previous demonstration of a substantial retention loss produced when learning occurs during a period of lowered body temperature (Richardson et al., 1983). Furthermore, the data indicate that the temporal onset and severity of amnesia was essentially the same in both deeply and moderately cooled subjects. This finding extends the earlier work by indicating that the anterograde amnesia does not depend upon overcooling and rewarming. Rats trained in a moderately hypothermic state showed forgetting regardless of the absolute level of zooling they initially received.

Of particular interest in this experiment is the relationship of temperature to the onset of amnesia. If temperature recovery were mirrored by a concurrent retention loss, then a strong case for a temperature dependent onset gradient could be made. If, however, subjects were to show retention while in a normothermic state, this would indicate a temperatureindependent onset of amnesia similar to that seen for hypothermia-induced retrograde amnesia (Mactutus \& Riccio, 1978).

Analysis of the colonic temperatures taken at the time of testing indicated that subjects that were cooled and tested at the 30-min interval (including the NCFS condition) had slightly, but significantly, lower temperatures than subjects in the retention control group $(z=3.04, p<.001)$. Furthermore, by $120 \mathrm{~min}$, temperature recovery was complete; subjects trained while cool but tested 120,360 , or 1,440 min after training did not differ significantly from the noncooled retention control group. Interestingly, when subjects' temperatures were slightly depressed, as was the case with the 30 -min group (median $34^{\circ} \mathrm{C}$ ), partial retention was obtained. However, subjects tested at $120 \mathrm{~min}$ also showed some retention with the TTW measure, yet their temperatures were normal (median $36^{\circ} \mathrm{C}$ ). Thus, while a precise relationship between temperature and onset of AA cannot be made at this point, it appears that temperature may be more important to the onset of AA than it is to onset of retrograde amnesia. If the onset of $\mathrm{AA}$ is indeed temperature dependent, then rapidly rewarming subjects after training should accelerate onset of AA, whereas keeping subjects cool would be expected to delay the onset. An experiment in progress is attempting to determine whether these manipulations will modulate the rate of onset of anterograde amnesia.

\section{GENERAL DISCUSSION}

These findings clearly demonstrate that hypothermia-induced anterograde amnesia is reversible. Subjects whose body temperatures at testing are comparable to those at training $\left(29^{\circ} \mathrm{C}\right)$ showed strong recovery of memory, whereas those tested at, or near, normothermic levels had very poor retention. The recovery cannot readily be attributed to any effects of systemic stress on test performance, because subjects receiving the same level of shock noncontingently along with the identical cooling/recooling exposures displayed brief cross-through latencies and short TTW scores. Clearly, then, stressed subjects are quite capable of locomotor activity; the hesitancy to return to the shock compartment in the recovery condition seems best explained as a genuine restoration of the earlier memory. This finding also bears on a perennial concern in studies of anterograde amnesia, that is, whether subjects did in fact acquire the original target information. The present finding of recovery of memory, in conjunction with data showing little or no retention loss in the anterograde condition when testing occurs immediately (Richardson et al., 1983 ) or $30 \mathrm{~min}$ (Experiment 2) after training, provides reassurance that the fear conditioning procedure was successful under the conditions employed here.

The role of body temperature (and concomitant internal changes) in governing memory retrieval is dramatically apparent with respect to recovery, where level of test performance was a graded function of level of hypothermia. Thus, reversal of anterograde amnesia was dependent on the extent to which body temperature at testing coincided with that at training. With respect to the onset of anterograde amnesia, however, the contribution of body temperature is not quite so clear. Generally speaking, the development of AA appears to increase as subjects return to normal temperature levels. Thus, at short test intervals, when the animals are still hypothermic, latency scores show strong retention, although some memory loss can be seen at $30 \mathrm{~min}$. At longer intervals, subjects have returned to normal body temperature and a profound anterograde amnesia is obtained. Several cautions about interpreting the role of body temperature in AA are in order, however. First, measurement of the amount of time spent on the safe side (TTW index) suggests that amnesia may not have reached an asymptotic level after $2 \mathrm{~h}$, despite recovery of body temperature to normal levels. Second, the approach in Experiment 2 was essentially correlational. It is conceivable that 
the anterograde me aory loss has a fixed time course of onset which coincidentally parallels the recovery of body temperature. Clarification of this possibility awaits the previously mentioned experimental analysis in which rate of temperature recovery is varied. Third, there is an interesting but puzzling disparity in amount of amnesia at two comparable absolute temperatures in the two experiments. In Experiment 2, only slight amnesia was obtained at the 30-min test, when subjects' median temperature was $34^{\circ} \mathrm{C}$. In contrast, in Experiment 1 subjects that had been recooled and tested when reaching $33^{\circ} \mathrm{C}$ showed no alleviation of amnesia. Granted the obvious procedural differences, and the fact that the comparison is across experiments conducted at different times, the finding suggests that the processes involved in the onset, and subsequent reversal, of anterograde amnesia are not simply mirror images of each other.

Although the formal similarity of anterograde amnesia paradigms using transient agents (e.g., ECS, hypothermia) and dissociative learning or statedependent-retention (SDR) paradigms is apparent, historically the two phenomena have usually been treated in the literature as separate entities. The present results provide strong support for the sporadically expressed view that the outcomes represent common processes (DeVietti \& Larson, 1971; Gardner et al., 1972; Overton, 1978). That memory recovery varies as a function of the similarity of body temperatures at training and at testing agrees well with predictions from a state-dependent model. Indeed, this outcome may be seen as a particularly compelling example of the general principle of cue-dependent retention. Memory retrieval occurs to the extent that the retrieval environment matches the encoding environment (see Lewis, 1976; Spear, 1973; Tulving \& Thomson, 1973).

As mentioned earlier, the increased amnesia obtained as a function of the disparity between training/testing conditions is also reminiscent of stimulus generalization decrement. However, this similarity is tempered by evidence that subjects trained at slightly warmer temperatures $\left(33^{\circ} \mathrm{C}\right)$ than those used here fail to display $\mathbf{A A}$, despite the fact that stimulus conditions are also mismatched at testing (Richardson et al., 1983). The importance of the absolute level of hypothermia for obtaining either anterograde or retrograde amnesia suggests the involvement of some central state after a certain threshold of cooling is exceeded. Similarly, drugs acting on the CNS seem to be far more potent in producing SDR than their peripherally acting analogues (Overton, 1966, 1978).

Two other aspects of the present findings with respect to SDR interpretations should be mentioned. First, it will be recognized that in terms of the traditional $2 \times 2$ design often employed in SDR studies, the present paradigm was "incomplete," lacking a group trained while normothermic and tested while hypothermic. However, this condition was included in an earlier study on RA, and no disruption of retention was seen (Hinderliter et al., 1975). Thus, the overall pattern of results is congruent with the asymmetrical dissociation frequently found in statedependent retention studies (e.g., Chute, 1978; Ebner, Richardson, \& Riccio, 1981; Weingartner, 1978). Second, tracking of the onset of amnesia does not appear to have a parallel data base in the SDR literature, presumably because a convenient independent index of drug state is usually lacking. The relatively close relationship between postacquisition changes in body temperature and the development of amnesia (Experiment 2) suggests that short-term examination of retention changes may also be fruitful in delineating the characteristics of drug-induced SDR.

Do the present findings offer any insights into anterograde amnesia in humans? This question is not answered easily. Although there has been considerable research on anterograde amnesia in humans (cf. Cermak, 1982; Whitty \& Zangwill, 1977), it has become increasingly clear in recent years that the exact nature of the amnestic syndrome in humans is not well understood. This uncertainty as to the nature of the amnesic syndrome in humans results mainly from two factors. First of all, the etiology of anterograde amnesia in humans is very diverse. For example, patients suffering from Korsakoff's syndrome, Alzeheimer's disease, "transient global amnesia", syndrome, surgical or accidental destruction of brain tissue, or concussive injury, as well as those receiving electroconvulsive shock therapy, have been included in studies on amnesia in humans (e.g., see Butters \& Cermak, 1980; Hirst, 1982; Markowitsch, 1983; Schacter \& Crovitz, 1977; Squire \& Slater, 1978; Stern, 1981). It is now clear that the deficits exhibited by these different classes of patients are often different (Squire, 1981, 1982; Weingartner, Grafman, Boutelle, Kaye, \& Martin, 1983). Obviously, this makes any determination of the "core" amnestic syndrome difficult (cf. Hirst, 1982). A second difficulty in the work on human amnesics is that in addition to memory impairment, they often suffer from other deficits (cf. Mayes \& Meudell, 1983). These additional cognitive difficulties suffered by most humans amnesics make it difficult to conclude that a subsequent performance failure is due to a pure "memory" deficit and not the result of a problem in some other cognitive process. Furthermore, in many studies on anterograde amnesia in humans, it is not clear that subjects ever initially acquired the target information; as noted earlier, it seems doubtful that the notion of memory loss (i.e., amnesia) is appropriate as an explanation of a performance failure in a situation in which memory never existed. However, it appears that anterograde forgetting does occur in some types of human am- 
nesia in which the level of the initial encoding of target information is comparable to that of controls (e.g., Squire, 1981). We tentatively suggest that the state-dependent-like retrieval mechanisms demonstrated here to be important in experimentally induced amnesia in rats may also play an important role in at least some of these amnesias in humans (cf. Schacter \& Crovitz, 1977).

At a more general level, the application of paradigms derived from animal learning to assess human amnesia and the development of models of anterograde amnesia using animals are two strategies that may prove useful in elucidating basic psychobiological mechanisms in memory dysfunction. The "comparative neuropsychological" approach to alcoholic Korsakoff's disease described by OscarBerman $(1980,1984)$ is representative of the former tactic. An advantage of the second strategy, inolving animals as models, may be illustrated with respect to the long-standing question of whether anterograde forgetting is a special case of retrograde amnesia. In many instances of "anterograde" amnesia, it is difficult to rule out the possibility that direct effects of the amnestic insult continue into the postacquisition period. Thus, the forgetting may be based upon retrograde impairment, even though the amnestic incident occurred prior to the to-be-remembered episode. However, by using rats in a situation in which very rapid reversal of the amnestic treatment can be achieved, we have been able to demonstrate an anterograde memory loss that is largely, perhaps totally, independent of retrograde processes (Riccio, Richardson, \& Guanowsky, 1983).

Because experimentally induced amnesia often involves administration of an acute treatment for which the sequelae can be relatively easily monitored and controlled, determination of where and how the memory process is altered in amnesic subjects is greatly simplified. Also, as the typical laboratory amnestic agents produce no discernible additional cognitive deficits (other than inducing amnesia for the target information encoded at that time), complications in the interpretation of the amnestic effect are minimized. An understanding of experimentally induced amnesia in rats should help us to understand, once etiology and other cognitive deficits are taken into account, the human amnesic syndrome.

\section{REFERENCES}

Butters, N., \& Albert, M. S. (1982). Processes underlying failures to recall remote events. In L. S. Cermak (Ed.), Human memory and amnesia. Hillsdale, $\mathrm{NJ}$ : Erlbaum.

Butters, N., \& Cermak, L. S. (1980). Alcoholic Korsakoff's syndrome: An information-processing approach to amnesia. New York: Academic Press.

Campbelt, B. A., \& Teghtsoonian, R. (1958). Electrical and behavioral effects of different types of shock stimuli on the rat. Journal of Comparative and Physiological Psychology, 51, 185-192.
Cermak, L. S. (1982). Human memory and amnesia. Hillsdale, NJ: Erlbaum.

Chute, D. L. (1978). The engram: Lost and found. In B. T. Ho, D. W. Richards III, \& D. L. Chute (eds.), Drug discrimination and state dependent learning. New York: Academic Press.

DeVietTi, T. L., \& Larson, R. C. (1971). ECS effects: Evidence supporting state-dependent learning in rats. Journal of Comparative and Physiological Psychology, 74, 407-415.

Ebner, D. L., Richardson, R., \& Riccio, D. C. (1981). Ovarian hormones and retention of learned fear in rats. Behavioral and Neural Biology, 33, 45-58.

Gardner, E. L., Glick, S. D., \& Jarvik, M. E. (1972). ECS dissociation of learning and one-way cross-dissociation with physostigmine and scopolamine. Physiology \& Behavior, 8, 11-15.

Gelle R, A., \& J ARvik, M. E. (1968). The time relations of ECSinduced amnesia. Psychonomic Society, 12, 169-170.

Hinderliter, C. F., Webster, T., \& Riccio, D. C. (1975). Amnesia induced by hypothermia as a function of treatment-test interval and recooling in rats. Animal Learning \& Behavior, 3, 257-263.

Hirst, W. (1982). The amnesic syndrome: Descriptions and explanations. Psychological Bulletin, 91, 435-460.

Huppert, F. A., \& Piercy, M. (1978). Dissociation between learning and remembering in organic amnesia. Nature, 275, 317-318.

Kopp, R., Bohdanecky, Z., \& Jarvik, M. E. (1968). Proactive effect of a single electroconvulsive shock (ECS) on one-trial learning in mice. Journal of Comparative and Physiological Psychology, 65, 514-517.

LEWIS, D. J. (1976). A cognitive approach to experimental amnesia. American Journal of Psychology, 89, 51-80.

Mactutus, C. F., Ferek, J. M., \& Riccio, D. C. (1980). Amnesia induced by hyperthermia: An usually profound, yet reversible, memory loss. Behavioral and Neural Biology, 30, 260-277.

Mactutus, C. F., \& Riccio, D. C. (1978). Hypothermia-induced retrograde amnesia: Role of body temperature in memory retrieval. Physiological Psychology, 6, 18-22.

Mactutus, C. F., Riccio, D. C., \& FereK, J. M. (1979). Retrograde amnesia for old (reactivated) memory: Some anomalous characteristics. Science, 204, 1319-1320.

Markowitsch, H. J. (1983). Transient global amnesia. Neuroscience and Biobehavioral Reviews, 2, 35-44.

Mayes, A., \& Meudell, P. (1983). Amnesia in humans and other animals. In A. Mayes (Ed.), Memory in animals and humans. Berkshire, England: Van Nostrand Reinhold (UK).

Miller, R. R., \& Springer, A. D. (1972). Induced recovery of memory in rats following electroconvulsive shock. Physiology \& Behavior, 8, 645-651.

Oscar-Berman, M. (1980). Neuropsychological consequences of long-term chronic alcoholism. American Scientist, 68, 410-419.

Oscar-Berman, M. (1984). Comparative neuropsychology and alcoholic Korsakoff's disease. In N. Butters \& L. R. Squire (Eds.), Neuropsychology of memory. Guilford Press.

Overton, D. (1966). State-dependent learning produced by depressant and atropine-like drugs. Psychopharmacologia, 10, 6-31.

Overton, D. A. (1978). Major theories of state dependent learning. In B. T. Ho, D. W. Richards III, \& D. L. Chute (Eds.), Drug discrimination and state dependent learning. New York: Academic Press.

Riccio, D. C., Hodges, L. A., \& Randall, P. K. (1968). Retrograde amnesia produced by hypothermia in rats. Journal of Comparative and Physiological Psychology, 66, 618-622.

Riccio, D. C., Mactutus, C. F., Hinderliter, C. F., \& McCutcheon, K. (1979). Severity of amnesia and the effectiveness of reactivation treatment: Evidence for a retrieval process. Physiological Psychology, 7, 59-63. 
Riccio, D. C., Richardson, R., \& Guanowsky, V. (1983). Is anterograde amnesia a special case of retrograde amnesia? Behavioral Neuroscience, 97, 512-515.

Richardson, R., Ricco, D. C., \& Morilak, D. A. (1983). Anterograde memory loss induced by hypothermia in rats. Behavioral and Neural Biology, 37, 76-88.

Schacter, D. L., \& Crovitz, H. F. (1977). Memory function after closed head injury: A review of the quantitative research. Cortex, 13, 150-176.

Spear, N. E. (1973). Retrieval of memory in animals. Psychological Review, 80, 163-194.

Spear, N. E. (1978). The processing of memories: Forgetting and retention. Hillsdale, NJ: Erlbaum.

Springer, A. D., Schoel, W. M., \& Klinger, P. D. \& AgranOFF, B. W. (1975). Anterograde and retrograde effects of electroconvulsive shock and of puromycin on memory formation in the goldfish. Behavioral Biology, 13, 467-481.

Squire, L. R. (1981). Two forms of human amnesia: An analysis of forgetting. Journal of Neuroscience, 1, 635-640.

SquiRE, L. R. (1982). Comparisons between forms of amnesia: Some deficits are unique to Korsakoff's syndrome. Journal of Experimental Psychology: Learning, Memory and Cognition, 8, 560-571.

Squire, L. R., \& Slater, P. C. (1978). Anterograde and retrograde memory impairment in chronic amnesia. Neuropsychologia, 16, 313-322.

Stern, L. (1981). A review of theories of human amnesia. Memory \& Cognition, 9, 247-262.
Thompson, C. I., \& Grossman, L. B. (1972). Loss and recovery of long-term memory after ECS in rats: Evidence for state dependent recall. Journal of Comparative Psychology, 78, 248-254.

Thompson, C. I., \& NeELy, J. E. (1970). Dissociated learning in rats produced by electroconvulsive shock. Physiology \& Behavior, 5, 783-786.

Tulving, E., \& Thomson, D. M. (1973). Encoding specificity and retrieval processes in episodic memory. Psychological Review, 80, 352-373.

WEINGARTNER, H. (1978). Human state dependent learning. In B. T. Ho, D. W. Richards III, \& D. L. Chute (Eds.), Drug discrimination and state dependent learning. New York: Academic Press.

Weingarter, H., Grafman, J., Boutelle, W., Kaye, W., \& Martin, P. R. (1983). Forms of memory failure. Science, 221, 380-382.

Wetsel, W. C., Riccio, D. C., \& Hinderliter, C. F. (1976). Effects of artificial rewarming upon hypothermia-induced retrograde amnesia. Physiological Psychology, 4, 201-206.

WhitTy, C. W. M., \& Zangwill, O. L. (Eds.) (1977). Amnesia (2nd ed.). London: Buttersworths.

(Manuscript received December 5, 1983; revision accepted for publication March 21, 1984.) 